\title{
Imunoterapia sublingual ao látex e estudo de perfil alergénico - 3 casos
}

\section{Sublingual latex immunotherapy and allergenic profile study -3 cases}

Rev Port Imunoalergologia 2019;27 (2): I57-164

Filipe Benito-Garcia, Ângela Gaspar, Inês Mota, Mário Morais-Almeida

Centro de Imunoalergologia, Hospital CUF Descobertas, Lisboa

\section{RESUMO}

A alergia ao látex afeta determinados grupos de risco com distintos perfis de sensibilização. $O$ único extrato para imunoterapia sublingual ao látex (ITSL) é constituído essencialmente por proteínas Hev b 6 e Hev b 5. Descrevem-se três casos de anafilaxia ao látex (dois também com anafilaxia em contexto de síndrome látex-frutos) que foram submetidos a ITSL com sucesso. Ocorreu melhoria clínica (dois doentes assintomáticos em contacto com látex), com negativar ou reduzir marcado da IgE específica para látex e principais alergénios recombinantes ( $\mathrm{rHev}$ b 5 e rHev b 6), e em nenhum caso houve aparecimento de novas sensibilizações para recombinantes do látex após duração mínima de 3 anos de ITSL. A recomendação da ITSL deve ser efetuada de acordo com o perfil de sensibilização, que deve ser sempre realizado antes da decisão sobre ITSL para obter uma dessensibilização bem-sucedida. A ITSL revelou-se eficaz e segura na abordagem destes doentes, com melhoria na qualidade de vida.

Palavras-chave: Alergénios recombinantes, alergia ao látex, imunoterapia específica, síndrome látex-frutos.

\section{ABSTRACT}

Latex allergy affects selected populations, called high-risk groups. Latex sensitization profile differs between these risk groups. The commercially available sublingual latex immunotherapy (SLIT) extract is mostly constituted by Hev $b 6$ and Heb b 5 proteins. We described three clinical cases of patients with latex anaphylaxis (two also with anaphylaxis in the context of latex-fruit syndrome) who were successfully submitted to SLIT. In all cases, occurred clinical amelioration (two asymptomatic in 
contact with latex) and negative or marked reduction in specific lgE levels for latex and major recombinant allergens ( $r$ Hev $b 5$ and $r \mathrm{Hev} b$ 6). No new sensitizations were detected to recombinant latex-allergens after a course of SLIT with at least 3 years duration. The SLIT recommendation is made according to latex sensitization profile, which must always be evaluated before latex immunotherapy's decision in order to achieve a successful desensitization. This therapeutic option has proved to be effective and safe for the management of these patients, with an improvement in the patient's quality of life.

Keywords: Latex allergy, latex-fruit syndrome, recombinant allergens, specific imunotherapy.

\section{INTRODUÇÃO}

A tualmente, apesar de menor expressão, a alergia ao látex continua a ser um problema em indivíduos com múltiplas exposições a produtos de látex, por razões profissionais ou de saúde (indivíduos com espinha bífida e/ou submetidos a múltiplas cirurgias), caracterizados como grupos de risco'. Nestes doentes, apesar da evicção do contacto com produtos com látex ser considerada a abordagem mais eficaz, esta nem sempre se revela fácil, atendendo a que as proteínas do látex estão presentes na composição de muitos produtos de uso médico (luvas, cateteres, algálias, drenos, sondas, garrotes, entre outros) e de uso corrente (preservativos, bolas, balões, toucas, entre outros).

O látex natural é um produto extraído da árvore-da-borracha (seringeira ou Hevea brasiliensis). O seu conteúdo proteico varia entre I a $2 \%$ dos seus constituintes, tendo sido identificados mais de 240 polipéptidos com pesos moleculares compreendidos entre 4 a $200 \mathrm{kDa}$. Alguns destes péptidos permanecem inalterados após o processamento industrial, podendo atuar como alergénios potentes'. $\mathrm{Na}$ atualidade, 15 proteínas do látex foram caracterizadas e registadas como alergénios, de acordo com o Comité Internacional de Nomenclatura de Alergénios $^{1,2}$. São denominadas como $\mathrm{Hev}$ b e estão listadas no Quadro I. A maioria destes alergénios foi disponibilizada como recombinante, à exceção de Hev b 2, 4, 13 e 14. A vantagem de proteínas recombinantes, em detrimento de naturais, é a possibilidade de produção em grande quantidade com elevada reprodutibilidade e qualidade.
O estudo do perfil alergénico de sensibilização ao látex, por recurso a alergénios recombinantes e naturais purificados, em diferentes grupos de risco, tem demonstrado a existência de padrões de sensibilização distintos, que parecem variar consoante a via de exposição ao látex. Hev b 5 e Hev b 6 são alergénios principais envolvidos na sensibilização ao látex, particularmente em profissionais de saúde. Hev b I e Hev b 3 estão relacionados com doentes submetidos a múltiplas cirurgias, nomeadamente em doentes com espinha bífida ${ }^{1,3}$. Vários alergénios do látex foram identificados como estando envolvidos em fenómenos de reatividade cruzada entre o látex e plantas filogeneticamente distantes, nomeadamente quitinases de classe I (Hev b 6 e Hev b II), $\beta$-I,3-glucanase (Hev b 2), patatina do látex (Hev b 7), proteína ácida do látex (Hev b 5), profilina do látex (Hev b 8) e proteína de transferência de lípidos não específica (Hev b 12)!

A possibilidade de cada grupo populacional, com diferentes vias de exposição, se sensibilizar especificamente a determinadas proteínas, permite explicar particularidades clínicas de cada grupo de risco, nomeadamente em relação à presença e gravidade da síndrome látex-frutos (SLF). Nos doentes alérgicos ao látex com exposição ocupacional a este alergénio, esta forma de alergia alimentar por reatividade cruzada é frequente; pelo contrário, nas crianças com espinha bífida esta síndrome é rara $^{4}$.

O diagnóstico através de alergénios moleculares permite ainda distinguir entre doentes com risco elevado de anafilaxia e doentes assintomáticos polissensibilizados. $A$ profilina Hev b 8, proteína do citoesqueleto existente na 
Quadro I. Alergénios do látex ${ }^{1,2}$

\begin{tabular}{|c|c|c|}
\hline Nomenclatura & Nome & Significado \\
\hline Hev b I & $\begin{array}{l}\text { REF } \\
\text { (fator de alongamento da borracha) }\end{array}$ & alergénio major (EB) \\
\hline Hev b 2 & $\beta$-I,3-glucanase & alergénio major (PS) \\
\hline Hev b 3 & $\begin{array}{l}\text { REF-like } \\
\text { (proteína das pequenas partículas de borracha) }\end{array}$ & alergénio major (EB) \\
\hline Hev b 4 & Componente da micro-hélice & alergénio minor \\
\hline Hev b 5 & Proteína ácida do látex & alergénio major (PS) \\
\hline Hev b 6 & $\begin{array}{l}\text { Proheveína (Hev b 6.01) } \\
\text { Heveína (Hev b 6.02) }\end{array}$ & $\begin{array}{l}\text { alergénio major (PS) } \\
\text { (Hev b 6.01 e Hev b 6.02) }\end{array}$ \\
\hline Hev b 7 & Patatina-like & alergénio minor \\
\hline Hev b 8 & Profilina do látex & alergénio minor \\
\hline Hev b 9 & Enolase do látex & alergénio minor \\
\hline Hev b I0 & Superóxido dismutase & alergénio minor \\
\hline Hev b I I & Quitinase da classe I & alergénio minor \\
\hline Hev b I 2 & LTP (proteína de transferência de lípidos não específica) do látex & alergénio minor \\
\hline Hev b I 3 & Esterase do látex & alergénio major (PS) \\
\hline Hev b I4 & Hevamina & ND \\
\hline Hev b I5 & Inibidor de serina protease do látex & ND \\
\hline
\end{tabular}

EB - indivíduos com espinha bífida; PS - profissionais de saúde; ND - não determinado

maioria das plantas (panalergénio), não está relacionada com clínica de reações alérgicas ao látex, sendo considerada um marcador de sensibilização assintomática ao látex!.

A imunoterapia específica permite uma dessensibilização a longo prazo, com redução dos sintomas na exposição ao alergénio e modificação na história natural da doença'. A imunoterapia específica sublingual ao látex (ITSL) tem-se revelado promissora, com reacções adversas mínimas e autolimitadas no entanto, por existir risco de reação sistémica no período de indução, esta deve ser sempre efetuada em meio hospitalar. $\bigcirc$ único extrato disponível comercialmente preconiza a administração numa fase de indução de 5 concentrações crescentes ao longo de 4 dias $\left(5 \times 10^{-8}\right.$,
$5 \times 10^{-5}, 5 \times 10^{-2}, 5$ e $\left.500 \mu \mathrm{g} / \mathrm{mL}\right)$, em meio hospitalar sob a supervisão de especialista, e uma fase de manutenção com 5 gotas sublinguais em 3 administrações por semana ou 2 gotas sublinguais em administrações diárias (Quadro 2) ${ }^{1,5}$. Segundo informação veiculada pelo fabricante (ALK-Abelló ${ }^{\circledR}$ ), o extrato da ITSL é maioritariamente composto por Hev b $6(5-6 \mu \mathrm{g} / \mathrm{mL})$, contendo baixa quantidade, mas detetável, de Hev b 5 e vestígios de Hev b $2^{\prime}$.

Consideram-se candidatos à ITSL os doentes com alergia respiratória e/ou anafilaxia em contacto com látex ou SLF. Assim, são os profissionais de saúde, por apresentarem maior sensibilização a Hev b 6 e Hev b 5 os principais candidatos a ITSL com sucesso com este extrato, enquanto nos indivíduos submetidos a múltiplas 
Quadro 2. Protocolo de imunoterapia específica sublingual ao látex ${ }^{1,5}$

\begin{tabular}{|c|c|c|c|}
\hline Dia & Frasco & N. ${ }^{\circ}$ de gotas & Dose $\mu \mathrm{g}$ \\
\hline \multicolumn{4}{|c|}{ Fase de indução } \\
\hline $\begin{array}{l}\text { I } \\
15 / 15 \mathrm{~min}\end{array}$ & $\begin{array}{l}\text { Frasco } 0 \\
5 \times 10^{-8} \mu \mathrm{g} / \mathrm{mL} \\
\text { Frasco I } \\
5 \times 10^{-5} \mu \mathrm{g} / \mathrm{mL}\end{array}$ & $\begin{array}{c}1 \\
10 \\
1 \\
10\end{array}$ & $\begin{array}{l}2 \times 10^{-9} \\
2 \times 10^{-8} \\
2 \times 10^{-6} \\
2 \times 10^{-5}\end{array}$ \\
\hline $\begin{array}{l}2 \\
15 / 15 \mathrm{~min}\end{array}$ & $\begin{array}{l}\text { Frasco } 2 \\
5 \times 10^{-2} \mu \mathrm{g} / \mathrm{mL} \\
\text { Frasco } 3 \\
5 \mu \mathrm{g} / \mathrm{mL}\end{array}$ & $\begin{array}{c}1 \\
10 \\
1 \\
10\end{array}$ & $\begin{array}{c}0,002 \\
0,02 \\
0,2 \\
2\end{array}$ \\
\hline $\begin{array}{l}3 \\
15 / 15 \mathrm{~min}\end{array}$ & $\begin{array}{l}\text { Frasco } 4 \\
500 \mu g / m L\end{array}$ & $\begin{array}{c}1 \\
2 \\
3 \\
4 \\
10\end{array}$ & $\begin{array}{c}20 \\
40 \\
60 \\
80 \\
200\end{array}$ \\
\hline 4 & $\begin{array}{l}\text { Frasco } 4 \\
500 \mu \mathrm{g} / \mathrm{mL}\end{array}$ & 25 & 500 \\
\hline \multicolumn{4}{|c|}{ Fase de manutenção } \\
\hline & $\begin{array}{l}\text { Frasco } 4 \\
500 \mu \mathrm{g} / \mathrm{mL}\end{array}$ & \multicolumn{2}{|c|}{$\begin{array}{c}5 \text { gotas } 3 \times / \text { semana } \\
\text { ou } \\
2 \text { gotas } / \text { dia }\end{array}$} \\
\hline
\end{tabular}

cirurgias a ITSL deverá ser considerada apenas em casos com comprovada sensibilização ao Hev b 6 '.

Descrevem-se 3 casos clínicos de anafilaxia ao látex que foram submetidos a tratamento com ITSL (SLIT-Latex ${ }^{\circledR}$, ALK-Abelló) com mais de 3 anos de duração. Antes de iniciar a imunoterapia ( $\mathrm{TI}$ ) todos os doentes foram avaliados por: testes cutâneos por picada (TC) com látex (extrato ALK-Abelló ${ }^{\circledR}$ ) e com alimentos com reatividade cruzada descrita com látex (extratos Leti ${ }^{\circledR}$ ); avaliação analítica com imunoglobulina E específica (slgE) (ImmunoCAP ${ }^{\circledR}$, ThermoFisher Scientific) para látex e para painel alargado de alergénios recombinantes de látex, incluindo $\mathrm{rHev}$ b I, rHev b 3, rHev b 5, rHev b 6.0I, rHev b 8, rHev b 9 e rHev b II. Esta mesma avaliação foi repetida após um ano e após um período de pelo menos 3 anos (TF) de duração da imunoterapia.

\section{CASO CLÍNICO I}

Mulher de 43 anos, enfermeira, com alergia ao látex. Após início da atividade ocupacional, refere queixas de urticária de contacto e rinoconjuntivite alérgica relacionadas com a utilização de luvas de látex no local de trabalho, motivo pelo qual passou a usar luvas de nitrilo. Em evicção de contacto com material contendo látex, refere posteriormente queixas de asma e rinoconjuntivite associadas ao manusear das luvas de látex pelos colegas no trabalho. Em 2002, refere episódio de anafilaxia (edema facial, rinoconjuntivite e dificuldade respiratória) imediatamente após contacto com material contendo látex no trabalho, que regrediu após broncodilatador inalado e terapêutica parentérica com anti-histamínico e corticosteroide. Não tinha antecedentes de intervenções cirúrgicas.

Foram realizados $\mathrm{TC}$ com látex (pápula 7,5mm) e com alimentos com reatividade cruzada descrita com látex que foram positivos para ananás $(4,5 \mathrm{~mm})$ e castanha $(5,5 \mathrm{~mm})$, sendo alimentos que não ingeria regularmente, pelo que ficou em evicção; restantes alimentos negativos (abacate, banana, kiwi, manga, maracujá, pêssego, uva, batata, tomate e espinafre).

$\mathrm{Na}$ avaliação analítica inicial (TI), lgE total $44 \mathrm{UI} / \mathrm{mL}$, slgE para látex positiva ( $10,5 \mathrm{kU} / \mathrm{L})$ e slgE para alergénios do látex positiva para rHev b 5 (I,48kU/L) e rHev b 6.0I $(\mathrm{I}, 20 \mathrm{kU} / \mathrm{L})$; negativa para restantes recombinantes $(\mathrm{rHev}$ b I, rHev b 3, rHev b 8, rHev b 9 e rHev b II).

Foi-lhe atribuída doença profissional por alergia ao látex. Usa cartão identificador de alerta médico e foi medicada com dispositivo autoinjetor de adrenalina $0,3 \mathrm{mg}$ por via intramuscular. Foi indicada evicção de exposição ao látex nas atividades diárias, incluindo profissionais, com uso exclusivo de luvas de nitrilo pela própria e uso de luvas sem pó lubrificante pelos colegas de trabalho. Evicção de material contendo látex durante qualquer ato médico ou cirúrgico, devendo a realização de cirurgia ser efetuada no primeiro tempo operatório para evitar contacto com alergénios de látex em suspensão. Evicção 
alimentar de ananás e castanha, frutos a que está sensibilizada e que não ingere regularmente.

Iniciou ITSL em 2005, tendo efectuado a fase de indução em meio hospitalar de acordo com o protocolo do fabricante (SLIT-Latex ${ }^{\circledR}$, ALK-Abelló) em 4 dias, no Hospital-de-Dia de Imunoalergologia (Quadro 2). Nesta fase, as reações adversas foram mínimas e autolimitadas: síndrome de alergia oral após as doses, crise de rinite no segundo dia, urticária da face e prurido ocular no terceiro dia, e prurido facial, auricular, palmar e plantar no quarto dia da indução.

$\mathrm{Na}$ fase de manutenção, o tratamento prosseguiu em ambulatório, com a autoadministração de 5 gotas sublin-

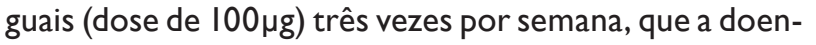
te cumpriu durante 5 anos, sem reações adversas. Após este período (TF), foram repetidos os TC com látex e com os alimentos com reatividade cruzada com látex, que foram negativos. Da avaliação analítica destaca-se a slgE para látex e para alergénios recombinantes ( $\mathrm{rHev} b$ I, rHev b 3, rHev b 5, rHev b 6.0I, rHev b 8, rHev b 9 e rHev b II), negativas. Nessa altura, foi submetida a prova de provocação, teste de uso com luva de látex, que foi negativa. A doente mantém-se assintomática em exposição ao látex, com contactos acidentais com materiais contendo látex, sem reação adversa.

\section{CASO CLÍNICO 2}

Homem de 59 anos, cirurgião, com alergia ao látex e SLF. Após início da atividade ocupacional refere urticária de contacto e rinoconjuntivite alérgica, após utilização de luvas de látex, motivo pelo qual passou a usar luvas de nitrilo. Posteriormente refere queixas de asma associadas ao manusear das luvas de látex pelos colegas de trabalho. Em 2006, refere episódio de anafilaxia (urticária generalizada, edema facial, rinoconjuntivite, edema da glote e dificuldade respiratória) no trabalho (serviço de urgência) imediatamente após utilização acidental de luvas de látex, que regrediu após administração de adrenalina intramuscular e anti-histamínico e corticosteróide endo- venosos. Posteriormente refere mais 3 episódios de anafilaxia após ingestão de alimentos com reatividade cruzada com látex: em 2007 episódio de anafilaxia (urticária generalizada, edema da glote e dificuldade respiratória) imediato após ingestão de pimentão, e 2 episódios semeIhantes, com prurido generalizado, edema labial e pieira, após ingestão de abacate e banana. Refere ainda queixas de urticária generalizada após ingestão de castanha, kiwi e papaia. Tinha antecedentes prévios de cirurgia oftalmológica sem intercorrências.

Foram realizados TC com látex (pápula 9,5mm) e com alimentos com reatividade cruzada com látex que foram positivos para abacate $(4,5 \mathrm{~mm})$, banana $(3 \mathrm{~mm})$, castanha $(7,5 \mathrm{~mm})$, kiwi $(5 \mathrm{~mm})$, maracujá $(3 \mathrm{~mm})$, papaia $(4 \mathrm{~mm})$ e pimentão $(10,5 \mathrm{~mm})$; restantes testes negativos (ananás, figo, manga, melão, pêssego, uva, batata, tomate e espinafre). Da avaliação analítica salienta-se lgE total 76, IUI/mL e slgE positivas para látex (14,6 kU/L), abacate $(2,0 \mathrm{kU} / \mathrm{L})$ e banana $(7,23 \mathrm{kU} / \mathrm{L})$; estudo do perfil de sensibilização com slgE para alergénios do látex positivas para rHev b 5 (I,94kU/L) e rHev b 6.0 I $(2,73 \mathrm{kU} / \mathrm{L})$, negativa para restantes recombinantes $(\mathrm{rHev} b \mathrm{I}, \mathrm{rHev} b$ 3, rHev b 8, rHev b 9 e rHev b II).

Foi-lhe atribuída doença profissional por alergia ao látex. Usa cartão de alerta médico e foi medicado com dispositivo autoinjector de adrenalina. Foi indicada evicção de exposição ao látex nas atividades diárias, incluindo profissionais, com uso exclusivo de luvas de nitrilo pelo próprio e pelos colegas de trabalho. Evicção alimentar de abacate, banana, castanha, kiwi, maracujá, papaia e pimentão.

Iniciou ITSL em 2008, tendo efetuado a fase de indução em meio hospitalar, de acordo com protocolo descrito em 4 dias. Nesta fase, as reações adversas foram imediatas e autolimitadas: síndrome de alergia oral após as doses e urticária facial no quarto dia da indução.

$\mathrm{Na}$ fase de manutenção, o tratamento prosseguiu em ambulatório, com a autoadministração de 2 gotas sublinguais diárias (dose de $40 \mu \mathrm{g}$ ), que o doente cumpriu durante 3 anos e 6 meses, sem reações adversas. 
Após este período (TF), foram repetidos os TC com látex (com redução da pápula para $6 \mathrm{~mm}$ ) e com os alimentos com reatividade cruzada com látex, que foram negativos. Da avaliação analítica destaca-se a redução da slgE para látex (I,68kU/L) e para o alergénio $r H e v b 6.0$ I (2,0lkU/L), com negativar das slgE para abacate, banana e alergénio rHev b 5, mantendo-se negativos os restantes recombinantes ( $\mathrm{rHev}$ b I, rHev b $3, \mathrm{rHev}$ b $8, \mathrm{rHev}$ b 9 e rHev b II). Atualmente o doente encontra-se assintomático em exposição ao látex, com contactos acidentais. De referir também a ingestão acidental de castanha e de pimentão, sem reação adversa.

\section{CASO CLÍNICO 3}

Mulher de 44 anos, professora, com antecedentes de 15 cirurgias (por pé boto e uma cesariana), com alergia ao látex e SLF. Após a última cirurgia, sem intercorrências, refere em 2005 episódio de anafilaxia (urticária generalizada, edema periorbitário e dos lábios, estridor laríngeo e pieira) imediato após contacto com balão. Refere ainda pieira após contacto com tapete contendo látex e episódio de rinite, conjuntivite e pieira após inalação de cheiro de borracha. Nesse ano, refere mais dois episódios de anafilaxia (urticária generalizada, edema labial, aperto orofaríngeo e dificuldade respiratória) imediatamente após ingestão de banana e de maracujá. Refere ainda pieira após contacto com figo.

Foram realizados TC com látex (pápula $8,5 \mathrm{~mm}$ ) e alimentos com reatividade cruzada com látex, que foram positivos para abacate $(3,5 \mathrm{~mm})$, banana $(3 \mathrm{~mm})$, castanha $(5,5 \mathrm{~mm})$, figo $(4 \mathrm{~mm})$, maracujá $(3 \mathrm{~mm})$ e pêssego $(4 \mathrm{~mm})$; restantes testes negativos (ananás, kiwi, manga, melão, uva, batata, tomate e espinafre). Da avaliação analítica salienta-se $\mathrm{IgE}$ total $79 \mathrm{UI} / \mathrm{mL}$ e slgE positivas para látex (17,2kU/L), banana (I,42 kU/L), castanha (10,2kU/L) e maracujá $(2,23 \mathrm{kU} / \mathrm{L})$; estudo do perfil de sensibilização com slgE positivas para os alergénios $\mathrm{rHev}$ b 5 ( $15,9 \mathrm{kU} / \mathrm{L})$, rHev b 6.01 (I7,3kU/L) e rHev b II (I,36kU/L), negativa para restantes recombinantes ( $\mathrm{rHev} b \mathrm{I}, \mathrm{rHev} b 3, \mathrm{rHev}$ b 8 e rHev b 9).

Usa cartão de alerta médico e foi medicada com dispositivo autoinjetor de adrenalina. Foi indicada evicção de exposição ao látex nas atividades diárias e evicção de material contendo látex durante qualquer ato médico ou cirúrgico. Evicção alimentar de abacate, banana, castanha, figo, maracujá e pêssego.

Iniciou ITSL em 20II, tendo efetuado a fase de indução em meio hospitalar, de acordo com protocolo referido em 4 dias. Nesta fase, as reações adversas foram imediatas e autolimitadas: síndrome de alergia oral após as doses, prurido facial no segundo dia, rinite e prurido auricular no terceiro dia, rinite e eritema facial no quarto dia da indução.

$\mathrm{Na}$ fase de manutenção, o tratamento prosseguiu em ambulatório, com a autoadministração de 2 gotas sublinguais diárias (dose de $40 \mu \mathrm{g}$ ), que a doente cumpriu durante 4 anos, sem reações adversas.

Após este período (TF), foram repetidos os TC com látex (com redução da pápula para $4 \mathrm{~mm}$ ) e com os alimentos com reatividade cruzada descrita com látex, que foram negativos. Da avaliação analítica destaca-se a redução da slgE para látex $(0,62 \mathrm{kU} / \mathrm{L})$ e para o alergénio rHev b 6.0 l (0,56kU/L), com negativar das slgE para banana, castanha, maracujá e para os alergénios rHev b 5 e rHev b II, mantendo-se negativos os restantes recombinantes ( $\mathrm{rHev}$ b I, rHev b 3, rHev b 8 e rHev b 9). Atualmente a doente encontra-se assintomática em exposição acidental ao látex, nomeadamente sem queixas após inalação de cheiro de borracha. De referir também a ingestão acidental de banana sem reação adversa.

\section{DISCUSSÃO}

Descrevem-se três casos de anafilaxia ao látex (dois também com anafilaxia em contexto de SLF) que foram submetidos a ITSL com sucesso. Após uma fase de manutenção com duração mínima de 3 anos, ocorreu meIhoria clínica após exposição ao látex (dois doentes as- 
sintomáticos no contacto com látex). Os valores dos doseamentos séricos das slgE para látex e principais alergénios recombinantes ( $\mathrm{rHev}$ b 5 e rHev b 6) negativaram ou sofreram uma redução marcada após a fase de manutenção, bem como negativaram ou sofreram uma redução marcada os TC com látex e alimentos implicados na SLF. Dois doentes passaram a tolerar alimentos implicados na SLF a que previamente reagiam (castanha e pimentão num caso, banana noutro caso). Importa ainda salientar o não aparecimento de novas sensibilizações aos recombinantes do látex após ITSL, com duração mínima de 3 anos, num caso após 5 anos de ITSL.

Relativamente à dessensibilização, a fase de indução foi completada, em todos os doentes, de forma positiva, apenas com aparecimento de reações adversas ligeiras, essencialmente mucocutâneas ou síndrome de alergia oral. Durante a fase de manutenção não houve reações adversas.

Patriarca et $a .^{6}{ }^{6}$, em 2002, descreveram um estudo controlado com placebo em que 12 doentes foram submetidos a ITSL com fase de indução e de manutenção similares aos doentes apresentados, obtendo o mesmo perfil de segurança. Durante a fase de indução os doentes não apresentaram efeitos adversos e, durante a fase de manutenção, só dois doentes apresentaram sintomas mucocutâneos ligeiros. Em 2006, Bernardini et al.' realizaram um estudo aleatorizado, em dupla ocultação controlado por placebo, no qual 12 doentes foram submetidos a ITSL sem descrição de reações adversas.

Em Portugal, em 2008, num estudo de ITSL em 22 doentes ${ }^{5}$, durante I ano, verificou-se na fase de indução a ocorrência de reações sistémicas ligeiras ou moderadas em $50 \%$ dos doentes. Spínola Santos et al. ${ }^{5}$ alertam para o risco de novas sensibilizações no decurso de ITSL que se verificou em 3 doentes.

Em 20II, Gastaminza et al. ${ }^{8}$, num estudo aleatorizado, em dupla ocultação controlado por placebo, incluíram 28 doentes que foram aleatorizados para receber ITSL ou placebo durante um ano, seguido de tratamento ativo, em fase aberta. Do total dos doentes incluídos, só 19 doentes completaram os 2 anos. Durante a fase de indução ocorreram 4 reações ligeiras no grupo ativo e durante a fase de manutenção 2 doentes desistiram por queixas de prurido e agudização de dermatite, respetivamente.

Apesar de o presente estudo incluir uma pequena amostra de doentes (série de 3 doentes), a segurança da ITSL foi comparável a outros estudos mais consistentes, comprovando a segurança desta opção terapêutica nestes doentes.

Relativamente a eficácia, e apesar de não ter sido objetivado com provas de provocação em todos os doentes, estes reportam ausência de sintomas na exposição acidental ao látex após a fase de manutenção. Este grupo de doentes que anteriormente tinha reações graves, potencialmente fatais, hoje em dia e em particular no caso da doente que fez 5 anos de ITSL, encontra-se num estado de tolerância que lhes permite conviverem com o látex sem reação alérgica. Ao longo dos anos, vários autores têm descrito resultados positivos relativamente à eficácia da ITSL em doentes com alergia ao látex. Patriarca et $a l^{6}$ descreveram uma diminuição de slgE para látex em sete doentes e uma melhoria significativa nas provas de provocação sublingual, conjuntival e cutânea, ao fim de três meses de seguimento; no grupo placebo não se identificaram variações nos scores de sintomas. No estudo de Gastaminza et al. ${ }^{8}$ foram avaliados diversos parâmetros, no início do estudo e ao fim de um ano e de dois anos de seguimento: TC, teste de uso com luva de látex, prova de provocação conjuntival, slgE e teste de ativação de basófilos (TAB). Não se encontraram diferenças significativas em nenhuma das variáveis, exceto diminuição da percentagem de basófilos ativados no TAB no grupo ativo, comparado com placebo após 2 anos de ITSL. Em 2012, Lasa Luaces et al. ${ }^{9}$ incluíram 23 doentes com alergia ao látex num estudo prospetivo, observacional, aberto, caso-controlo. Desses, 18 foram submetidos a ITSL e foram avaliados vários parâmetros ao fim de 6 meses e de 12 meses de tratamento: TC, prova de provocação conjuntival, slgE e lgG4 específicas, slgE para alergénios recombinantes do látex e TAB. Apesar de não se verifi- 
carem alterações significativas nos doseamentos de slgE, houve um aumento de lgG4 nos doentes tratados e uma diminuição significativa no TAB com os alergénios do látex implicados.

Em 2017, Sridharan et al. ${ }^{10}$, numa revisão sistemática com o objetivo de avaliar a eficácia da ITSL, incluíram quatro estudos aleatorizados e controlados por placebo na meta-análise. Foram avaliados diversos parâmetros, nomeadamente sintomas, teste de uso de luva de látex, TC e slgE para látex. De salientar uma redução significativa no teste de uso de látex em dois estudos. Até à data, os estudos aleatorizados e controlados por placebo englobam um pequeno número de doentes e a maioria dos estudos realizados foram pouco consistentes, não conseguindo objetivar de forma sistemática diversos parâmetros.

A recomendação da ITSL deve ser efetuada de acordo com o perfil alergénico de sensibilização ao látex, que deve ser sempre realizado antes da decisão sobre ITSL para obter uma dessensibilização bem-sucedida. A ITSL revelou-se uma opção terapêutica eficaz e segura na abordagem destes doentes, com melhoria na qualidade de vida.

\section{Conflito de interesses}

Os autores declaram que não existem conflitos de interesse.

Contacto:

Ângela Gaspar

Centro de Imunoalergologia, Hospital CUF Descobertas

Rua Mário Botas, 1998-018 Lisboa

E-mail: angela.gaspar@sapo.pt

\section{REFERÊNCIAS}

I. Gaspar A, Faria E. Alergia ao látex. Rev Port Imunoalergologia 2012;20:173-92.

2. Rihs HP, Sander I, Heimann H, Meurer U, Bruning T, Raulf M. The new latex allergen Hev b I5: IgE-binding properties of a recombinant serine protease inhibitor. J Investig Allergol Clin Immunol 2015;25:160-2.

3. Raulf-Heimsoth M, Rihs HP, Rozynek P, Cremer R, Gaspar A, Pires $G$, et al. Quantitative analysis of immunoglobulin E reactivity profiles in patients allergic or sensitized to natural rubber latex (Hevea brasiliensis). Clin Exp Allergy 2007;37:1657-67.

4. Gaspar A, Pires G, Matos V, Loureiro V, Morais-Almeida M, Rosado-PintoJ. Prevalência e factores de risco para síndrome látex-frutos em doentes com alergia ao látex. Rev Port Imunoalergol 2004; 12:209-23.

5. Spínola Santos A, Lopes da Silva S, Alves R, Pedro E, Pereira Santos MC, Pereira Barbosa M. Imunoterapia sublingual ao látex: avaliação da segurança e de novas sensibilizações. Rev Port Imunoalergologia 2008;16:149-62.

6. Patriarca G, Nucera E, Pollastrini E, Roncallo C, Buonomo A, Bartolozzi F, et al. Sublingual desensitization: a new approach to latex allergy problem. Anesth Analg 2002;95:956-60.

7. Bernardini R, Campodonico P, Burastero S, Azzari C, Novembre $E$, Pucci $N$, et al. Sublingual immunotherapy with a latex extract in paediatric patients: a double-blind, placebo-controlled study. Curr Med Res Opin 2006;22:1515-22.

8. Gastaminza G, Algorta J, Uriel O, Audicana MT, Fernandez E, Sanz ML, et al. Randomized, double-blind, placebo-controlled clinical trial of sublingual immunotherapy in natural rubber latex allergic patients. Trials 2011;12:191.

9. Lasa Luaces EM, Tabar Purroy Al, García Figueroa BE, Anda Apiñaniz M, Sanz Laruga ML, Raulf-Heimsoth M, et al. Component-resolved immunologic modifications, efficacy, and tolerance of latex sublingual immunotherapy in children. Ann Allergy Asthma Immunol 2012;108:367-72.

10. Sridharan K, Sivaramakrishnan G. Sublingual immunotherapy in patients with latex allergy: systematic review and meta-analysis of randomized controlled trials. J Dermatolog Treat 2017;28:600-5. 